\title{
The deleterious effect of the HLA-C1/KIR2DL3 receptor-ligand combination in Chinese HIV patients
}

Jian-jun Sun

Shanghai Public Health Clinical Center

Jia-yin Shen

Shanghai Public Health Clinical Center

Feng-di Zhang

Shanghai Public Health Clinical Center

\section{Ren-fang Zhang}

Shanghai Public Health Clinical Center

Li Liu

Shanghai Public Health Clinical Center

Yin-zhong Shen

Shanghai Public Health Clinical Center

Jiang-rong Wang

Shanghai Public Health Clinical Center

Tang-kai Qi

Shanghai Public Health Clinical Center

Zhen-yan Wang

Shanghai Public Health Clinical Center

Yang Tang

Shanghai Public Health Clinical Center

Wei Song

Shanghai Public Health Clinical Center

Jun Chen

Shanghai Public Health Clinical Center

\section{Li-qian Guan}

Shanghai Public Health Clinical Center

\section{Mei-yan Sun}

Shanghai Public Health Clinical Center

Shu-ye Zhang

Shanghai Public Health Clinical Center

Hong-zhou Lu ( $\nabla$ luhongzhou@fudan.edu.cn )

Shanghai Public Health Clinical Center 
Research article

Keywords: NK cell, viral set point, ratio of CD4/CD8, immune activation, KIR, soluble CD14

Posted Date: November 2nd, 2020

DOI: https://doi.org/10.21203/rs.2.22572/v2

License: (c) (i) This work is licensed under a Creative Commons Attribution 4.0 International License. Read Full License 


\section{Abstract}

Background The combination of KIR-HLA affects the prognosis of HIV infection, and polymorphisms of KIR and its ligand HLA differs between regions and races. Few research has focused on the effects of the KIR-HLA combination on the prognosis of HIV-infected individuals in China.

Methods Peripheral blood samples were collected from newly diagnosed and treatment naïve HIVinfected patients and processed according to the study design. Their clinical data and other demographic information were recorded. The genomic DNA of the host was extracted from whole blood samples, and KIR genotyping was performed using sequence specific primer amplification (PCR-SSP). The HLA genotyping was performed using sequence analysis (PCR-SBT), and the HLA-KIR genotyping and combination information were obtained. Fisher's exact test was used for the comparison of categorical variables between groups, and the Mann-Whitney test was used for continuous variables.

Results The baseline HIV level in patients with an HLA-C1+/KIR2DL3+ background was significantly higher than that in patients with an HLA-C1+/KIR2DL3- $\left(4.34 \log _{10}\right.$ copies $/ \mathrm{ml}$ vs. $3.72 \log _{10} \mathrm{copies} / \mathrm{ml}$, $P=0.02)$. The baseline $C D 4 / C D 8$ ratio of $H L A-C 1+/ K I R 2 D L 3+$ patients was significantly lower than that of HLA-C1+/KIR2DL3- patients (0.33 vs. 0.56, $P=0.02)$. The plasma soluble CD14 level at baseline was significantly lower in HLA-C1+/KIR2DL3-infected persons than HLA-C1+/KIR2DL3+ patients $(P=0.03)$.

Conclusions HIV-infected persons with the combination of HLA-C1+/KIR2DL3+ had a much higher HIV set point, higher baseline SCD14 levels and lower baseline CD4/CD8 than patients without this combination. The receptor-ligand combination of HLA-C1+/KIR2DL3+ has a deleterious effect in Chinese HIV patients.

\section{Background}

The effect of the innate immune system is directly related to the prognosis of HIV infection[1]. Natural killer (NK) cells are important cellular subsets of the innate immune system[2]. The interaction between the NK cell immunoglobulin-like receptor (KIR) and its ligand, type I human leukocyte antigen (HLA), modulates the activity of NK cells. Previous studies[3,4] showed that KIR and its ligands, type I HLA genes, are extremely rich in genetic polymorphisms. A particular kind of HLA molecule is only identified via specific KIRs: the combination of HLA-C1 and KIR2DL2/2DL3[5, 6] and the match of HLA-Bw4 and KIR3DL1/S1[7, 8]. Clinical studies[9, 10] found that HIV-infected patients with different HLA/KIR combinations have different infection outcomes. For example, the progression to AIDS is slower in patients with the combination of HLA-Bw4 and KIR3DS1 than other patients. However, Carrington M et al. [11] suggested that polymorphisms of KIR and its ligand HLA differed between regions and races. However, little research has focused on the effects of the combination of KIR-HLA on the prognosis of HIV-infected individuals in China.

Previous studies $[12,13]$ found that the level of viral set point directly affected the rate of progression of HIV. Notably, the baseline CD4/CD8 ratio is an important indicator for the progression of HIV[14-16]. The 
rate of progression to AIDS is much slower in patients with baseline CD4/CD8 >1[14]. After effective antiviral therapy controls a patient's CD4/CD8 ratio to remain below 0.5 , the occurrence of non-AIDS related diseases, such as cardiovascular disease or cancer risk, increases significantly[15]. The expression level of certain inflammatory markers, such as elevated soluble CD14 levels, also predicts the morbidity and mortality of non-AIDS disease in HIV-infected patients[17, 18].

Previous studies[19-21] demonstrated that the combination of KIR-HLA affected the prognosis of HIV infection in Caucasians and Africans. Therefore, we hypothesized that specific KIR and HLA combinations in Chinese HIV-infected patients would impact the viral set point, CD4/CD8 ratio, and soluble CD14 levels.

\section{Methods And Materials}

\section{Study subjects}

\section{Inclusion criteria}

I. From December 2015 to May 2016, the patient in the clinic of Shanghai Public Health Clinical Center who visited for the first time was able to follow up on schedule

II. HIV infection was confirmed on Western blot

III. No previous use of antiviral treatment

IV. Age $>18$ years

V. Ability to sign informed consent.

\section{Exclusion criteria}

I. Patients with opportunistic infections and tumors, such as pulmonary tuberculosis, cryptococcal meningitis, or severe pulmonary infection, lymphoma

II. Due to personal reasons, reluctant to initiate antiviral treatment

III. Does not match the definition of HIV set point.

\section{The definition of HIV set point}

5-12 months after the estimated infection date; or with estimated infection date more than one year, CD4 cell counts greater than 350 cells $/ \mathrm{mm}^{3}$ and no symptoms of AIDS.

\section{Participants' clinical data}

We reviewed participants' demographic characteristics (gender, age, infection routes, marital status, and HIV confirmed time) and disease relevant information (CD4 counts, HIV-RNA load, and CD4/CD8 ratio) from the Hospital Information System (HIS). Blood samples for HIV-RNA load and CD4+ T-cell count measurement were analyzed using COBAS TaqMan(RocheDiagnostics, Inc. Rotkreuz, Switzerland) and 
CYTOMICS-FC500(Beckman Coulter, Inc. Brea, USA), respectively, at the Shanghai Public Health Clinical Center affiliated with Fudan University. HIV-1 genotypic and antiviral drug resistance analyses were performed using the Stanford University HIV Drug Resistance Database(http://hivdb.stanford.edu/) and the method described in the previous study[22].

\section{Healthy volunteers}

Nineteen healthy volunteers ( 15 males and 4 females) were recruited in the Shanghai Public Health Clinical Center in May 2016. After informed consent, $20 \mathrm{ml}$ of peripheral blood was collected. There were no significant differences in demographic data, such as age and gender, between the healthy controls and patients with HIV infection ( $P>0.05)$.

\section{KIR and HLA genotyping and SCD14 determination}

The determination of KIR genotype was based on a reliable multiplex PCR-SSP (sequence-specific priming) method for the relatively rapid and inexpensive genotyping of $15 \mathrm{KIR}$ genes using standard agarose gel electrophoresis, as described by Kulkarni $S$ et al.[23]. First, Genomic DNA was extracted from peripheral blood samples using a DNA extractor kit (QuickGene-Mini80; FUJIFILM Co., Ltd., Japan) according to the manufacturer's instructions. The quality and quantity of the extracted DNA samples were determined using UV spectrophotometry (NANODROP2000; Thermo Scientific Co., Ltd.). DNA samples were stored at $-20^{\circ} \mathrm{C}$ for further use. Genotyping of the KIR was performed to detect the presence or absence of 16 KIR loci (KIR2DL1-5, 2DS1-5, 3DL1-3, 3DS1 and 2DP1, DRB1) using PCR amplification with PCR-SSP, as described previously[23]. DRB1 was the internal standard. A PCR cocktail of $120 \mu$ (sufficient for 15 wells) of one sample was prepared as follows: $10 \mu$ INA template(100ng/ul), $20 \mu$ l PCR buffer, 10

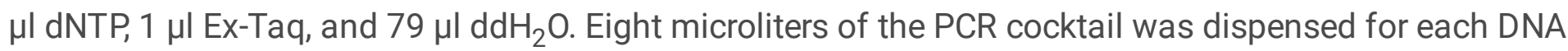
sample to each primer mix $(2 \mu \mathrm{l})$ in the plate for a total PCR volume of $10 \mu \mathrm{l}$. The amplification was carried out in a programmable PCR thermal cycler with a heated lid to minimize evaporation using the following program: $3 \mathrm{~min}$ at $94^{\circ} \mathrm{C}, 5$ cycles of $15 \mathrm{~s}$ at $94^{\circ} \mathrm{C}, 15 \mathrm{~s}$ at $65^{\circ} \mathrm{C}, 30 \mathrm{~s}$ at $72^{\circ} \mathrm{C}, 21$ cycles of $15 \mathrm{~s}$ at $94^{\circ} \mathrm{C}, 15 \mathrm{~s}$ at $60^{\circ} \mathrm{C}, 30 \mathrm{~s}$ at $72^{\circ} \mathrm{C}, 4$ cycles of $15 \mathrm{~s}$ at $94^{\circ} \mathrm{C}, 1 \mathrm{~min}$ at $55^{\circ} \mathrm{C}, 2 \mathrm{~min}$ at $72^{\circ} \mathrm{C}$ followed by a final 7 min extension step at $72^{\circ} \mathrm{C}$. The reaction products were run in $3 \%$ agarose gels for electrophoresis to determine the presence of the genes. The gel was visualized using a UV light source, and the gel was photographed for a permanent record. The appearance of the amplicon band of the expected molecular weight indicated the presence of the gene in the genomic DNA sample.

The determination of HLA genotype was modified from the method of PCR and sequence-based typing, which was reported elsewhere[24]. PCR of the HLA was performed to obtain the products of 4 amplicons of HLA-B2/B3, HLA-C2/C3. A PCR cocktail of $368 \mu \mathrm{l}$ (sufficient for 4 wells) for one sample was prepared as follows: $8 \mu$ INA template (100 ng/ul), $40 \mu \mathrm{l} \mathrm{PCR} \mathrm{buffer,} 32 \mu \mathrm{dNTP}, 4 \mu \mathrm{l} \mathrm{Ex-Taq,} \mathrm{and} 284 \mu \mathrm{ddH}_{2} \mathrm{O}$. The PCR cocktail $(46 \mu \mathrm{l})$ was dispensed for each DNA sample to each primer mix $(4 \mu \mathrm{l})$ in the plate for a total PCR volume of $50 \mu \mathrm{l}$. The amplification was carried out in a programmable PCR thermal cycler with a heated lid to minimize evaporation using the following program: $3 \mathrm{~min}$ at $95^{\circ} \mathrm{C}, 35$ cycles of $25 \mathrm{~s}$ at 
$95^{\circ} \mathrm{C}, 45 \mathrm{~s}$ at $60^{\circ} \mathrm{C}, 45 \mathrm{~s}$ at $72^{\circ} \mathrm{C}$, and $8 \mathrm{~min}$ at $72^{\circ} \mathrm{C}$. The reaction products were run in $1.5 \%$ agarose gels for electrophoresis to determine the presence of amplicons. If there was a corresponding amplicon band, the PCR product was sent for purification and sequencing. The sequence of sequencing primers was the same as the amplification primers. The HLA-B and HLA-C genotypes were performed using GENDX software (GenDx Company, Yalelaan 48 Utrecht, 3584 CM Netherlands). The HLA gene, allele group and specific HLA protein were recorded according to the standard of the HLA Nomenclature Committee of the WHO. According to the differences in amino acids at positions 77 and 80 of the a heavy chain of HLA-B and C, HLA-B molecules were divided into two types: Bw4 type (Ser77/Thr80, Asp77/Thr80, Asn77/Thr80 or Asn77/lle80) and Bw6 (Gly77/Asn80 or Ser77/Asn80). HLA-C was divided into C1 (Ser77/Asn80) and C2 (Asn77/Lys80).

The plasma biomarker of gut bacterial translocation LPS/LBP and the marker of immune activation sCD14 were measured using an ELISA kit (R\&D Co. Ltd.; RayBiotech Co. Ltd.; Abbexa Co. Ltd.) according to the manufacturer's instructions. Plasma concentrations were compared between HIV-infected patients and healthy controls.

\section{Statistical Analysis}

Continuous variables are described using medians and interquartile ranges (IQR), and categorical variables are described as numbers and percentages. Fisher's exact test was used for the comparison of categorical variables between groups and the Mann-Whitney test was used for continuous variables. All hypothesis testing was 2 -sided with a level of $a=0.05$. Data analyses were performed using IBM SPSS version 19.0 (IBM SPSS, Inc., Armonk, NY, USA), and the figures were constructed using GraphPad Prism version 5.0 (GraphPad Software, Inc., San Diego, CA, USA).

\section{Results}

Most of the HIV patients were transmitted via sex contact, and the median age was 32 years. Among the distribution of HIV subtypes in all 116 cases, the largest number of subtypes was CRF-01AE (68 cases), followed by subtypes B and C. Ten HIV patients were drug-resistance positive. According to the results of sequence alignment, these 10 patients were divided into three groups: low, moderate and high drug resistance. Two patients were resistant to protease inhibitors, 7 patients were resistant to non-nucleoside reverse transcriptase inhibitors, and 1 patient was resistant to nucleoside (see Table 1).

\section{Table 1. The demographics and clinical data of the eligible patients}




\begin{tabular}{|c|c|c|}
\hline Demographics and clinical data & & All Subjects $(n=116)$ \\
\hline Age & & $31.50(27.25-39.75)$ \\
\hline \multirow[t]{2}{*}{ Gender } & Male & 113 \\
\hline & Female & 3 \\
\hline \multirow[t]{4}{*}{ Infection routes } & Homosexual & 90 \\
\hline & Heterosexual & 20 \\
\hline & blood $^{\square}$ & 1 \\
\hline & undetermined & 5 \\
\hline HIV set point ${ }^{\square}$ & (Median, IQR) & $4.25(3.72-4.70)$ \\
\hline Baseline CD4 & (Median, IQR) & $327(254-436)$ \\
\hline Baseline Ratio of CD4/CD8 & (Median, IQR) & $0.34(0.25-0.51)$ \\
\hline \multirow[t]{3}{*}{ HIV subtypes } & $\mathrm{CRF}-01 \mathrm{AE}$ & 68 \\
\hline & B & 41 \\
\hline & C & 7 \\
\hline \multirow[t]{2}{*}{ Drug-resistance } & Yes & 10 \\
\hline & No & 106 \\
\hline
\end{tabular}

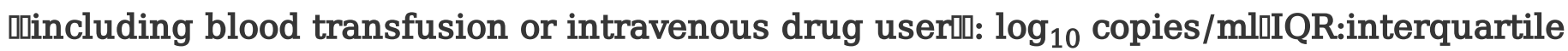
range.

Among the 116 subjects, the DRB1 gene was the internal control, and all of the 116 patients were 2DL4, 3DL2 and 3DL3 positive. Twenty patients were 2DS3 positive. The percentages of 2DL4, 3DL2 and 3DL3 were $100 \%, 100 \%$ and $97 \%$, respectively. The rest of the KIR gene-positive patients accounted for $17 \%$ $-99 \%$ of the total subjects (Supplementary Figure S1). There were 83 alleles of HLA-B in the 116 HIVinfected individuals. Only allele frequencies above $1 \%$ are shown in Supplementary Figure S2. The HLA-B allele distribution was more dispersed in the infected individuals. The highest frequency HLA-B13:01 accounted for $6.9 \%$, and HLA-B46:47 accounted for $1.3 \%$. The distribution of HLA-C alleles was also relatively scattered. There were $76 \mathrm{HLA}-\mathrm{C}$ alleles in the $116 \mathrm{HIV}$-infected persons. Supplementary Figure S3 shows that only allele frequencies above 1\% were typed. The highest frequency was HLA-C01:02, which accounted for $12.1 \%$, and HLA-C12:30 accounted for 1.3\% (see Supplementary Figure S3).

HLA-Bw4 carriers were the most prevalent (63.8\%) in all of the subjects. HLA-C1 carriers accounted for $93.1 \%$ of all subjects, and homozygous HLA-C2/C2 accounted for only $7 \%$ of the total patients. Patients with the ligand-receptor combination of HLA-C1/KIR2DL3 had a much higher HIV set point and lower ratio of baseline CD4/CD8. There were no significant differences between HLA-Bw4+/KIR3DS1+ and HLABw4+/KIR3DS1- HIV infected persons in viral set point $(P>0.05)$. Patients with HLA-Bw6+/KIR3DS1+ or HLA-Bw6+/KIR3DS1- also showed no significant differences in viral set point. However, the viral set point was significantly higher for patients with the HLA-C1+/KIR2DL3+ combination than the HLAC1+/KIR2DL3- combination $(P<0.05)$ (see Table 2). 
Table 2. Comparison of HIV set point between different ligand-receptor combinations of HLA/KIR

\begin{tabular}{|c|c|c|c|c|c|c|}
\hline \multirow[t]{2}{*}{ HLA genotypes } & \multirow{2}{*}{$\begin{array}{l}\text { KIR } \\
\text { genotypes }\end{array}$} & \multicolumn{5}{|c|}{ HIV set point $\left(\log _{10}\right.$ copies $\left./ \mathrm{ml}\right)$ (Median, IQR ) } \\
\hline & & \multicolumn{2}{|l|}{$\operatorname{KIR}(+)$} & \multicolumn{2}{|l|}{ KIR(-) } & \multirow{2}{*}{$P$ value } \\
\hline $\begin{array}{l}\text { HLA-Bw4+ } \\
\text { n=74 }\end{array}$ & KIR3DL1 & $\mathrm{n}=73$ & $\begin{array}{l}4.24(3.62- \\
-4.68)\end{array}$ & $\mathrm{n}=1$ & NA & \\
\hline & KIR3DS1 & $\mathrm{n}=21$ & $\begin{array}{l}4.43(3.64- \\
-5.02)\end{array}$ & $\mathrm{n}=53$ & $\begin{array}{l}4.15(3.61- \\
-4.63)\end{array}$ & 0.22 \\
\hline \multirow[t]{2}{*}{$\begin{array}{l}\text { HLA-Bw4-80I+ } \\
\text { n=35 }\end{array}$} & KIR3DL1 & $\mathrm{n}=35$ & $\begin{array}{l}4.33 \text { ( } 3.62-- \\
4.66)\end{array}$ & $\mathrm{n}=0$ & NA & -- \\
\hline & KIR3DS1 & $\mathrm{n}=9$ & $\begin{array}{l}4.43(3.58-- \\
5.29)\end{array}$ & $\mathrm{n}=26$ & $\begin{array}{l}4.28 \text { ( } 3.61-- \\
4.66)\end{array}$ & 0.72 \\
\hline \multirow[t]{2}{*}{$\begin{array}{l}\text { HLA-Bw6+ } \\
\mathrm{n}=97\end{array}$} & KIR3DL1 & $\mathrm{n}=95$ & $\begin{array}{l}4.33(3.81- \\
4.74)\end{array}$ & $\mathrm{n}=2$ & $\begin{array}{l}4.23(3.85-- \\
4.60)\end{array}$ & -- \\
\hline & KIR3DS1 & $\mathrm{n}=27$ & $\begin{array}{l}4.43(3.72- \\
4.74)\end{array}$ & $\mathrm{n}=70$ & $\begin{array}{l}4.28(3.83- \\
4.75)\end{array}$ & 0.91 \\
\hline \multirow[t]{3}{*}{$\begin{array}{l}\text { HLA-C1+ } \\
\mathrm{n}=108\end{array}$} & KIR2DL2 & $\mathrm{n}=41$ & $\begin{array}{l}4.43(3.71- \\
4.99)\end{array}$ & $\mathrm{n}=67$ & $\begin{array}{l}4.25(3.78-- \\
4.66)\end{array}$ & 0.86 \\
\hline & KIR2DL3 & $\mathrm{n}=102$ & $\begin{array}{l}4.34(3.77- \\
4.74)\end{array}$ & $\mathrm{n}=6$ & $\begin{array}{l}3.72(3.50- \\
3.85)\end{array}$ & 0.02 \\
\hline & KIR2DS2 & $\mathrm{n}=29$ & $\begin{array}{l}4.24(3.56- \\
4.86)\end{array}$ & $\mathrm{n}=79$ & $\begin{array}{l}4.33(3.82- \\
-4.69)\end{array}$ & 0.28 \\
\hline HLA-C2+ $\quad n=29$ & KIR2DL1 & $\mathrm{n}=28$ & $\begin{array}{l}4.06(3.49- \\
-4.33)\end{array}$ & $\mathrm{n}=1$ & NA & -- \\
\hline
\end{tabular}

NAПNot applicable凹IQR: interquartile range.

There were no significant differences in baseline CD4/CD8 ratios between patients with different HLABw4/KIR3D combinations and HLA-Bw6/KIR3D pairing combinations. However, the baseline CD4/CD8 ratio of HIV-infected persons with HLA-C1+/KIR2DL3- was significantly higher than patients with HLA$\mathrm{C} 1+/ \mathrm{KIR} 2 \mathrm{DL} 3+(\mathrm{P}=0.02)($ see Table 3$)$.

Table 3. Comparison of the ratio of baseline CD4/CD8 between different ligand-receptor combinations of HLA/KIR 


\begin{tabular}{|c|c|c|c|c|c|c|}
\hline \multirow[t]{2}{*}{ HLA genotypes } & \multirow{2}{*}{$\begin{array}{l}\text { KIR } \\
\text { genotypes }\end{array}$} & \multicolumn{5}{|c|}{ The ratio of baseline CD4/CD8 (Median, IQR ) } \\
\hline & & $\mathrm{KIR}(+)$ & & KIR(-) & & $P$ \\
\hline \multirow[t]{2}{*}{$\begin{array}{l}\text { HLA-Bw4+ } \\
\mathrm{n}=74\end{array}$} & KIR3DL1 & $\mathrm{n}=73$ & $\begin{array}{l}0.33(0.23- \\
-0.51)\end{array}$ & $\mathrm{n}=1$ & NA & -- \\
\hline & KIR3DS1 & $\mathrm{n}=21$ & $\begin{array}{l}0.35(0.26- \\
-0.58)\end{array}$ & $\mathrm{n}=53$ & $\begin{array}{l}0.31(0.23- \\
-0.46)\end{array}$ & 0.31 \\
\hline \multirow[t]{2}{*}{$\begin{array}{l}\text { HLA-Bw4-80I+ } \\
\mathrm{n}=35\end{array}$} & KIR3DL1 & $\mathrm{n}=35$ & $\begin{array}{l}0.31(0.23- \\
-0.51)\end{array}$ & $\mathrm{n}=0$ & NA & -- \\
\hline & KIR3DS1 & $\mathrm{n}=9$ & $\begin{array}{l}0.29(0.21- \\
-0.46)\end{array}$ & $\mathrm{n}=26$ & $\begin{array}{l}0.32(0.23- \\
-0.52)\end{array}$ & 0.72 \\
\hline \multirow[t]{2}{*}{$\begin{array}{l}\text { HLA-Bw6+ } \\
\text { n=97 }\end{array}$} & KIR3DL1 & $\mathrm{n}=95$ & $\begin{array}{l}0.33(0.25- \\
-0.49)\end{array}$ & $\mathrm{n}=2$ & $\begin{array}{l}0.52(0.47- \\
-0.56)\end{array}$ & -- \\
\hline & KIR3DS1 & $\mathrm{n}=27$ & $\begin{array}{l}0.34(0.28- \\
-0.56)\end{array}$ & $\mathrm{n}=70$ & $\begin{array}{l}0.33(0.25- \\
-0.48)\end{array}$ & 0.45 \\
\hline \multirow[t]{3}{*}{$\begin{array}{l}\text { HLA-C1+ } \\
\text { n=108 }\end{array}$} & KIR2DL2 & $\mathrm{n}=41$ & $\begin{array}{l}0.33(0.20- \\
-0.44)\end{array}$ & $\mathrm{n}=67$ & $\begin{array}{l}0.33(0.25- \\
-0.51)\end{array}$ & 0.31 \\
\hline & KIR2DL3 & $\mathrm{n}=102$ & $\begin{array}{l}0.33(0.25- \\
-0.49)\end{array}$ & $\mathrm{n}=6$ & $\begin{array}{l}0.56(0.39- \\
-0.84)\end{array}$ & 0.02 \\
\hline & KIR2DS2 & $\mathrm{n}=29$ & $\begin{array}{l}0.35(0.19- \\
-0.53)\end{array}$ & $\mathrm{n}=79$ & $\begin{array}{l}0.33(0.25- \\
-0.49)\end{array}$ & 0.96 \\
\hline HLA-C2+ $\quad n=29$ & KIR2DL1 & $\mathrm{n}=28$ & $\begin{array}{l}0.36(0.25- \\
0.50)\end{array}$ & $\mathrm{n}=1$ & NA & -- \\
\hline
\end{tabular}

\section{NADNot applicableđIQR:interquartile range.}

The baseline viral load of the HLA-C1+/KIR2DL3+ group was significantly higher than the HLA$\mathrm{C} 1+/$ KIR2DL3- group $(\mathrm{P}=0.02)$. However, the initiation and continuation of antiretroviral therapy rapidly decreased the viral load in both groups, and the difference in reduction gradually narrowed. By the end of the 6 month treatment period, there was no difference of viral load between the two groups (see Figure 1). From the baseline, there was a significant difference in the CD4/CD8 ratio between the two groups $(P=$ 0.02). The $C D 4 / C D 8$ ratio increased in both groups with the antiretroviral treatment. The HLA$\mathrm{C} 1+/ \mathrm{KIR} 2 \mathrm{DL} 3+$ group had a higher CD4/CD8 ratio at 6 months of treatment, but there was no significant difference between the two groups $(P=0.38)$.

The plasma LPS concentration of HIV-infected patients at baseline was significantly higher than healthy controls $(P<0.001)$. The plasma SCD14 level was significantly higher than healthy people, but there was no significant difference in plasma LBP level between the two groups (see Figure 2).

The plasma soluble CD14 level at baseline was significantly lower in patients with HLA-C1+/KIR2DL3than HLA-C1+/KIR2DL3+ $(P=0.03)$. There was no significant difference in soluble CD14 levels based on age or sex in the two groups. The baseline plasma LPS of HLA-C1+/KIR2DL3- HIV-infected patients was 
lower than HLA-C1+/KIR2DL3+ HIV-infected patients, and the plasma LBP level of the former group was higher than the latter group, but the difference was not statistically significant (see Table 4).

Table 4. The comparison of baseline plasma LPS, LBP and sCD14 between HIV patients with HLA-C1+/KIR2DL3+and HLA-C1+/KIR2DL3-

\begin{tabular}{|c|c|c|c|c|}
\hline $\begin{array}{l}\text { Demographics and clinical } \\
\text { data }\end{array}$ & $\begin{array}{l}\text { All HIV patients } \\
(\mathrm{n}=82)\end{array}$ & $\begin{array}{l}\text { HLA- } \\
\text { C1+/KIR2DL3- } \\
(\mathrm{n}=4) \\
\text { (Median, IQR) }\end{array}$ & $\begin{array}{l}\text { HLA- } \\
\text { C1+/KIR2DL3+ } \\
(\mathrm{n}=78) \\
\text { (Median, IQR) }\end{array}$ & $\begin{array}{l}\mathrm{P} \\
\text { value * }\end{array}$ \\
\hline Age(years $\square$ median, IQR) & $31.0(27.8-39.0)$ & $\begin{array}{l}25.5(21.3- \\
32.8)\end{array}$ & $\begin{array}{l}31.5(28.0- \\
39.5)\end{array}$ & 0.12 \\
\hline Gender(Male/Female) & $80 / 2$ & $4 / 0$ & $76 / 2$ & 1.0 \\
\hline $\begin{array}{l}\text { Baseline Viral load }\left(\log _{10}\right. \\
\text { copies } / \mathrm{ml} \text { ) }\end{array}$ & $4.23(3.71-4.66)$ & $\begin{array}{l}3.72(3.53- \\
4.06)\end{array}$ & $\begin{array}{l}4.33(3.71- \\
4.69)\end{array}$ & 0.10 \\
\hline Baseline CD4(cells/ul) & $\begin{array}{l}322(251.8- \\
426.5)\end{array}$ & $\begin{array}{l}417.5(262.5- \\
462.3)\end{array}$ & $\begin{array}{l}317.5(251.8- \\
421.5)\end{array}$ & 0.43 \\
\hline $\begin{array}{l}\text { Ratio of CD4/CD8(median, } \\
\text { IQR) }\end{array}$ & $\begin{array}{l}0.32(0.23- \\
0.50)\end{array}$ & $\begin{array}{l}0.56(0.34- \\
0.85)\end{array}$ & $\begin{array}{l}0.32(0.23- \\
0.49)\end{array}$ & 0.07 \\
\hline $\begin{array}{l}\text { Baseline plasma } \\
\text { LPS(ng/ml) }\end{array}$ & $376(218-539)$ & $261(141-700)$ & $378(222-539)$ & 0.43 \\
\hline $\begin{array}{l}\text { Baseline plasma } \\
\text { LBP(ug/ml) }\end{array}$ & $\begin{array}{l}10.94(8.41- \\
17.27)\end{array}$ & $\begin{array}{l}14.68(8.23- \\
28.54)\end{array}$ & $\begin{array}{l}10.49(8.32- \\
17.15)\end{array}$ & 0.51 \\
\hline $\begin{array}{l}\text { Baseline plasma } \\
\text { sCD14(ng/ml) }\end{array}$ & $\begin{array}{l}2677(2159- \\
3514)\end{array}$ & $\begin{array}{l}\text { 1711(1353- } \\
2553)\end{array}$ & $\begin{array}{l}2723(2174- \\
3548)\end{array}$ & 0.03 \\
\hline
\end{tabular}

* $\square$ P value were calculated by Fisher exact test or Mann-whitney testIIQRDinterquartile range.

\section{Discussion}

KIR and HLA molecules affect the pathogenesis and prognosis of many diseases because of their regulatory roles in NK cell immunity[25-28]. The results of HLA genotyping revealed that the frequencies of HLA-Bw4 and HLA-C1/C2 genotyping were basically the same as a previous HLA-B/C genotyping study in an Eastern Chinese population[29]. The frequency of KIR was also very similar to the results of non-HIV patients in Eastern China[29, 30].

The HIV set point level of the infected patients directly affects the rate of disease progression. According to previous studies[31-34], the level of HIV set point in the present study was defined as 5-12 months after the anticipated infection or the anticipated infection of more than 1 year and CD $4>350 / \mathrm{UL}$ without initiating anti-HIV treatment. For the effector of inhibitory KIR on NK cell, the role of HLA-A and HLA-B is weaker than HLA-C[35]. The present study found that the HIV-infected people with KIR2DL and its ligand HLA-C1 gene had a significantly different set point from others without the combination of KIR2DL/HLAC1. Patients with the combination of HLA-C1+/KIR2DL3+ had significantly higher levels than patients with HLA-C1+/KIR2DL3-. These results are consistent with a previous clinical cohort study in 
Thailand[19]. Our study found no significant difference between the KIR3DS1+/HLA-Bw4+ group and the KIR3DS1-/HLA-Bw4+ group with HIV infection. This results contradict previous studies[36, 37], which reported that patients with the combination of KIR3DS1+/HLA-Bw4+ showed a slower progression of HIV infection. There are several reasons for this difference. Previous studies focused on infection and control of the progress of the elite in the typical HIV (Elite controller) comparison between the KIR-HLA distributions, which are less involved in the common HIV infection group. The current study recruited common HIV patients, and we focused on the combination of HLA-KIR that affects the prognosis of HIV infection. The Nef protein of HIV reduces the expression level of HLA-A and HLA-B, but the HLA-C is maintained at the original level[38-40]. As a result, the level of HLA-Bw4, as the ligand for the NK cell activation receptor KIR3SD1, was down regulated, which weakens the ability to activate the NK immune effect and decreases the function. Consequently, the protective effect of HLA-Bw4/KIR3DS1 was reduced, but the expression of HLA-C1 and its ligand KIR2DL3, were maintained after HIV infection. Therefore, the combination of HLA-C1/KIR2DL3- down regulates the inhibition of NK cell immune effectors compared to KIR2DL3+, and NK cells play immunoprotective effects or delay the progression of HIV infection[41].

The clinical cohort study[19] in Thailand mentioned above found that the combination of HLAC1/KIR2DL3- was a protective factor for delaying the progression of HIV infection. Our study found that the viral set point and the baseline CD4/CD8 ratio support this conclusion. Because the level of immune activation is also an important factor in the progression of HIV infection, we further analyzed the effect of the HLA-C1/KIR2DL3 combination on the immune activation of HIV infection. We found that the plasma SCD14 level of infected persons with HLA-C1+/KIR2DL3+ was significantly higher than HLAC1+/KIR2DL3-HIV-infected persons, and the HIV set point of the former group was significantly higher than the latter group. As suggested by Anas A et al.[42], the level of SCD14 in plasma may be related to the increase of LPS and LBP due to intestinal microflora translocation and the level of the plasma HIV load. Therefore, the ability of HLA-C1+/KIR2DL3- to inhibit HIV replication is stronger than HLA$\mathrm{C} 1+/ \mathrm{KIR} 2 \mathrm{DL} 3+$, which weakens the HIV infection-induced immune activation. Consequently, this difference would cause the plasma level of SCD14 to become significantly lower in the former group than in the latter group. However, although the viral load of HIV-infected patients decreased significantly after 6 months of potent antiretroviral therapy, the plasma SCD14 level did not decrease accordingly, but increased significantly compared to the level at baseline. Many factors including HIV replication, antiviral drugs toxicity, co-infections, loss of regulatory cells, and microbial translocation affect immune activation[43] and thus affect the level of plasma SCD14. The relationship between the combination of HLA/KIR and SCD14 need further research.

There are some limitations in this study. First, there were only 6 patients without KIR2DL3. Although the differences in the study were statistically significant, caution in the interpretation of these results into clinical effects is warranted. The sample size should be expanded. Because of the small proportion of KIR molecules on the surface of CD8+ T lymphocytes, our study only discussed NK cells. The potential effects of CD8+ T cells cannot be excluded in this study, which is also a limitation. 


\section{Conclusions}

HIV-infected persons with the combination of HLA-C1+/KIR2DL3+ have a much higher HIV set point, higher baseline SCD14 levels and lower baseline CD4/CD8 than patients without this combination. The receptor-ligand combination of HLA-C1+/KIR2DL3+ has a deleterious effect in Chinese HIV patients.

\section{List Of Abbreviations}

HIV: human immunodeficiency virus; AIDS: acquired immunodeficiency syndrome; NK:Natural Killer; CDC: centers for disease control; IQR: interquartile range; IDU: injection drug use; HLA:Human Leukocyte Antigen; KIR: Killer Cell Immunoglobulin-Like Receptor; PCR: Polymerase Chain Reaction; SBT:Sequence Based Typing; LBP:Lipopolysaccharide Binding protein; LPS:Lipopolysaccharides; sCD14:Soluable CD14.

\section{Declarations}

\section{Ethical approval and consent to participate}

The study protocol was designed in accordance with the recommendations of Declaration of Helsinki and approved by the Shanghai Public Health Clinical Center Ethics Committee (Ethical number 2015-Y00802). All of the study participants were given written informed consent in accordance with the Declaration of Helsinki.

Consent for publication Not applicable.

Availability of data and materials All data generated or analysed during this study are included in this published article and its supplementary information files(S4 File).

Competing interests The authors declare that they have no competing interests.

Funding This study was supported by the grant of National Major Scientific and Technological Special Project for 'Significant New Drugs Development-Scientific and Technological Platform Construction for New Anti-HIV Drugs Clinical Assessment during the Thirteenth Five-year Plan Periodヌ2017ZX09304027》 and Shanghai Pujiang Talent Project(15PJ1407300)and National Natural Science Foundation Project(81571977) and the Medical Guidance Support Project of Shanghai Science and Technology Commission (No: 17411969600), Key Research grants from the Ministry of Science and Technology, the People's Republic of China (NO: 2017ZX10202101). The funders had no role in study design, data collection and analysis, decision to publish, or preparation of the manuscript.

Authors' contributors HZL, SYZ, JJS and JYS conceived and designed the study; JJS and LL,RFZ,JRW,YZS,JC,ZYW,YT,WS,TKQ,MYS,LQG,JC collected the data. JJS and JYS analyzed the data; JJS, JYS and SYZ,HZL interpreted the results; JJS and JYS wrote the first draft; JJS, JYS, HZL and SYZ contributed to the final version. All authors have read and approved the manuscript. 
Acknowledgments

We give our cordial thanks to Corky Steinhart who help us to improve our manuscript writing. We extend our thanks to the colleagues of HIV health care clinic and the staff in the Department of Infectious Disease of Shanghai Public Health Clinical Center which is a designated diagnosis and treatment center for HIV infected patients in East China. We also give our thanks to those patients and healthy volunteers who participated in our research.

\section{References}

[1] Seay K, Church C, Zheng J H, et al. In Vivo Activation of Human NK Cells by Treatment with an Interleukin-15 Superagonist Potently Inhibits Acute In Vivo HIV-1 Infection in Humanized Mice[J]. J Virol,2015,89(12):6264-6274.

[2] Jost S, Altfeld M. Control of human viral infections by natural killer cells[J]. Annu Rev Immunol,2013,31:163-194.

[3] Parham P, Moffett A. Variable NK cell receptors and their MHC class I ligands in immunity, reproduction and human evolution[J]. Nat Rev Immunol,2013,13(2):133-144.

[4] Abi-Rached L, Moesta A K, Rajalingam R, et al. Human-specific evolution and adaptation led to major qualitative differences in the variable receptors of human and chimpanzee natural killer cells[J]. PLoS Genet,2010,6(11):e1001192.

[5] Winter C C, Gumperz J E, Parham P, et al. Direct binding and functional transfer of NK cell inhibitory receptors reveal novel patterns of HLA-C allotype recognition[J]. J Immunol,1998,161(2):571-577.

[6] Korner C, Granoff M E, Amero M A, et al. Increased frequency and function of KIR2DL1-3(+) NK cells in primary HIV-1 infection are determined by HLA-C group haplotypes[J]. Eur J Immunol,2014,44(10):29382948.

[7] Campbell K S, Purdy A K. Structure/function of human killer cell immunoglobulin-like receptors: lessons from polymorphisms, evolution, crystal structures and mutations[J]. Immunology,2011,132(3):315-325.

[8] Stanietsky N, Mandelboim O. Paired NK cell receptors controlling NK cytotoxicity[J]. FEBS Lett,2010,584(24):4895-4900.

[9] Habegger D S A, Sinchi J L, Marinic K, et al. KIR-HLA-A and B alleles of the Bw4 epitope against HIV infection in discordant heterosexual couples in Chaco Argentina[J]. Immunology,2013,140(2):273-279.

[10] Koehler R N, Alter G, Tovanabutra S, et al. Natural killer cell-mediated innate sieve effect on HIV-1: the impact of KIR/HLA polymorphism on HIV-1 subtype-specific acquisition in east Africa[J]. J Infect Dis,2013,208(8):1250-1254. 
[11] Bashirova A A, Thomas R, Carrington M. HLA/KIR Restraint of HIV: Surviving the Fittest[J]. Annual Review of Immunology,2011,29(1):295-317.

[12] Lifson J D, Nowak M A, Goldstein S, et al. The extent of early viral replication is a critical determinant of the natural history of simian immunodeficiency virus infection[J]. J Virol,1997,71(12):9508-9514.

[13] Prentice H A, Tang J. HIV-1 dynamics: a reappraisal of host and viral factors, as well as methodological issues[J]. Viruses,2012,4(10):2080-2096.

[14] Tang J, Li X, Price M A, et al. CD4:CD8 lymphocyte ratio as a quantitative measure of immunologic health in HIV-1 infection: findings from an African cohort with prospective data[J]. Front Microbiol,2015,6:670.

[15] Hema M N, Ferry T, Dupon M, et al. Low CD4/CD8 Ratio Is Associated with Non AIDS-Defining Cancers in Patients on Antiretroviral Therapy: ANRS C08 (Aproco/Copilote) Prospective Cohort Study[J]. PLoS One,2016,11(8):e161594.

[16] Hoenigl M, Chaillon A, Little S J. CD4/CD8 Cell Ratio in Acute HIV Infection and the Impact of Early Antiretroviral Therapy[J]. Clin Infect Dis,2016,63(3):425-426.

[17] Sandler N G, Wand H, Roque A, et al. Plasma levels of soluble CD14 independently predict mortality in HIV infection[J]. J Infect Dis,2011,203(6):780-790.

[18] Hunt P W, Cao H L, Muzoora C, et al. Impact of CD8+ T-cell activation on CD4+ T-cell recovery and mortality in HIV-infected Ugandans initiating antiretroviral therapy[J]. AIDS,2011,25(17):2123-2131.

[19] Mori M, Wichukchinda N, Miyahara R, et al. The effect of KIR2D-HLA-C receptor-ligand interactions on clinical outcome in a HIV-1 CRF01_AE-infected Thai population[J]. AIDS,2015,29(13):1607-1615.

[20] Bachle S M, Malone D F, Buggert M, et al. Elevated levels of invariant natural killer T-cell and natural killer cell activation correlate with disease progression in HIV-1 and HIV-2 infections[J]. AIDS,2016,30(11):1713-1722.

[21] Song R, Lisovsky I, Lebouché B, et al. HIV Protective KIR3DL1/S1-HLA-B Genotypes Influence NK CellMediated Inhibition of HIV Replication in Autologous CD4 Targets[J]. PLoS Pathogens,2014,10(1):e1003867.

[22] Zhang F, Liu L, Sun M, et al. An analysis of drug resistance among people living with HIV/AIDS in Shanghai, China[J]. PLoS One,2017,12(2):e165110.

[23] Kulkarni S, Martin M P, Carrington M. KIR genotyping by multiplex PCR-SSP[J]. Methods Mol Biol,2010,612:365-375. 
[24] Trachtenberg E A, Holcomb C L. Next-generation HLA sequencing using the 454 GS FLX system[J]. Methods Mol Biol,2013,1034:197-219.

[25] Ayo C M, Reis P G, Dalalio M M D O, et al. Killer Cell Immunoglobulin-like Receptors and Their HLA Ligands are Related with the Immunopathology of Chagas Disease[J]. PLOS Neglected Tropical Diseases,2015,9(5):e3753.

[26] van Duin D, Avery R K, Hemachandra S, et al. KIR and HLA Interactions Are Associated With Control of Primary CMV Infection in Solid Organ Transplant Recipients[J]. American Journal of Transplantation,2014,14(1):156-162.

[27] Guo X, Zhang Y, Li J, et al. Strong influence of human leukocyte antigen (HLA)-DP gene variants on development of persistent chronic hepatitis B virus carriers in the Han Chinese population[J]. Hepatology,2011,53(2):422-428.

[28] Venstrom J M, Zheng J, Noor N, et al. KIR and HLA genotypes are associated with disease progression and survival following autologous hematopoietic stem cell transplantation for high-risk neuroblastoma[J]. Clin Cancer Res,2009,15(23):7330-7334.

[29] Jiang Y, Chen O, Cui C, et al. KIR3DS1/L1 and HLA-Bw4-80I are associated with HIV disease progression among HIV typical progressors and long-term nonprogressors[J]. BMC Infect Dis,2013,13:405.

[30] Lu C, Shen Y J, Deng Y F, et al. Association of killer cell immunoglobulin-like receptors with pulmonary tuberculosis in Chinese Han[J]. Genet Mol Res,2012,11(2):1370-1378.

[31] Roberts L, Passmore J A, Mlisana K, et al. Genital tract inflammation during early HIV-1 infection predicts higher plasma viral load set point in women[J]. J Infect Dis,2012,205(2):194-203.

[32] Zhang Z, Hu S, Liu J, et al. CD4+CD38+HLA-DR+ cells: a predictor of viral set point in Chinese men with primary HIV infection who have sex with men[J]. Jpn J Infect Dis,2011,64(5):423-425.

[33] Wei Z, Liu Y, Xu H, et al. Genome-Wide Association Studies of HIV-1 Host Control in Ethnically Diverse Chinese Populations[J]. Scientific Reports,2015,5:10879.

[34] Huang $X$, Chen $\mathrm{H}, \mathrm{Li} \mathrm{W}$, et al. Precise determination of time to reach viral load set point after acute HIV-1 infection[J]. J Acquir Immune Defic Syndr,2012,61(4):448-454.

[35] Ahlenstiel G, Martin M P, Gao X, et al. Distinct KIR/HLA compound genotypes affect the kinetics of human antiviral natural killer cell responses[J]. J Clin Invest,2008,118(3):1017-1026.

[36] Alter G, Rihn S, Walter K, et al. HLA class I subtype-dependent expansion of KIR3DS1+ and KIR3DL1+ NK cells during acute human immunodeficiency virus type 1 infection[J]. J Virol,2009,83(13):6798-6805. 
[37] Alter G, Martin M P, Teigen N, et al. Differential natural killer cell mediated inhibition of HIV-1 replication based on distinct KIR/HLA subtypes[J]. Journal of Experimental Medicine,2007,204(12):30273036.

[38] Cohen G B, Gandhi R T, Davis D M, et al. The selective downregulation of class I major histocompatibility complex proteins by HIV-1 protects HIV-infected cells from NK cells[J]. Immunity,1999,10(6):661-671.

[39] Martini F, Agrati C, D'Offizi G, et al. HLA-E up-regulation induced by HIV infection may directly contribute to CD94-mediated impairment of NK cells[J]. Int J Immunopathol Pharmacol,2005,18(2):269276.

[40] Le Gall S, Erdtmann L, Benichou S, et al. Nef interacts with the mu subunit of clathrin adaptor complexes and reveals a cryptic sorting signal in MHC I molecules[J]. Immunity,1998,8(4):483-495.

[41] Korner C, Granoff M E, Amero M A, et al. Increased frequency and function of KIR2DL1-3(+) NK cells in primary HIV-1 infection are determined by HLA-C group haplotypes[J]. Eur J Immunol,2014,44(10):2938-2948.

[42] Anas A, van der Poll T, de Vos A F. Role of CD14 in lung inflammation and infection[J]. Crit Care,2010,14(2):209.

[43] Deeks SG, Lewin SR, Havlir DV. The end of AIDS: HIV infection as a chronic disease[J]. Lancet. 2013,382:1525-1533.

\section{Figures}


Figure 1. Trends of HIV-RNA load from ART initiation to 6 months after

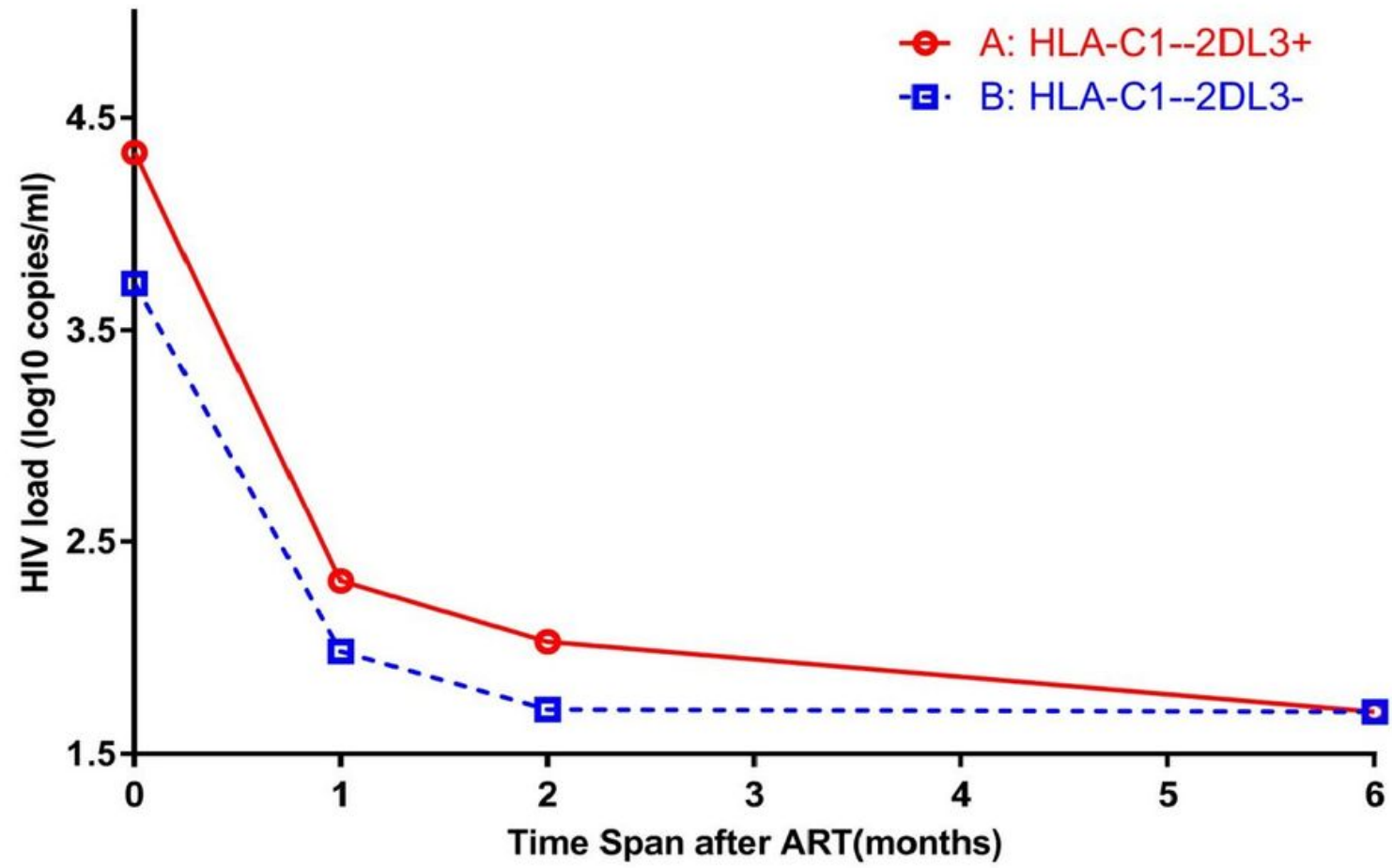

\begin{tabular}{|c|c|c|c|c|c|c|c|c|c|}
\hline GROUP A & 0M & $1 \mathrm{M}$ & $2 \mathrm{M}$ & $6 \mathrm{M}$ & GROUP B & $0 \mathrm{M}$ & $1 \mathrm{M}$ & $2 \mathrm{M}$ & $6 \mathrm{M}$ \\
\hline Nubmer & 102 & 101 & 101 & 82 & Nubmer & 6 & 6 & 6 & 5 \\
\hline 1/4 IQR & 3.8 & 2.0 & 1.7 & 1.3 & $1 / 4$ IQR & 3.5 & 1.6 & 1.3 & 1.3 \\
\hline Median & 4.3 & 2.3 & 2.0 & 1.7 & Median & 3.7 & 2.0 & 1.7 & 1.7 \\
\hline 3/4 IQR & 4.7 & 2.7 & 2.4 & 1.7 & $3 / 4$ IQR & 3.8 & 2.1 & 2.1 & 1.7 \\
\hline
\end{tabular}

Figure 1

Trends of HIV-RNA load from ART initiation to 6 months after. 
Figure 2. The comparison of baseline plasma LPS, LBP and SCD14 between HIV patients and healthy volunteers

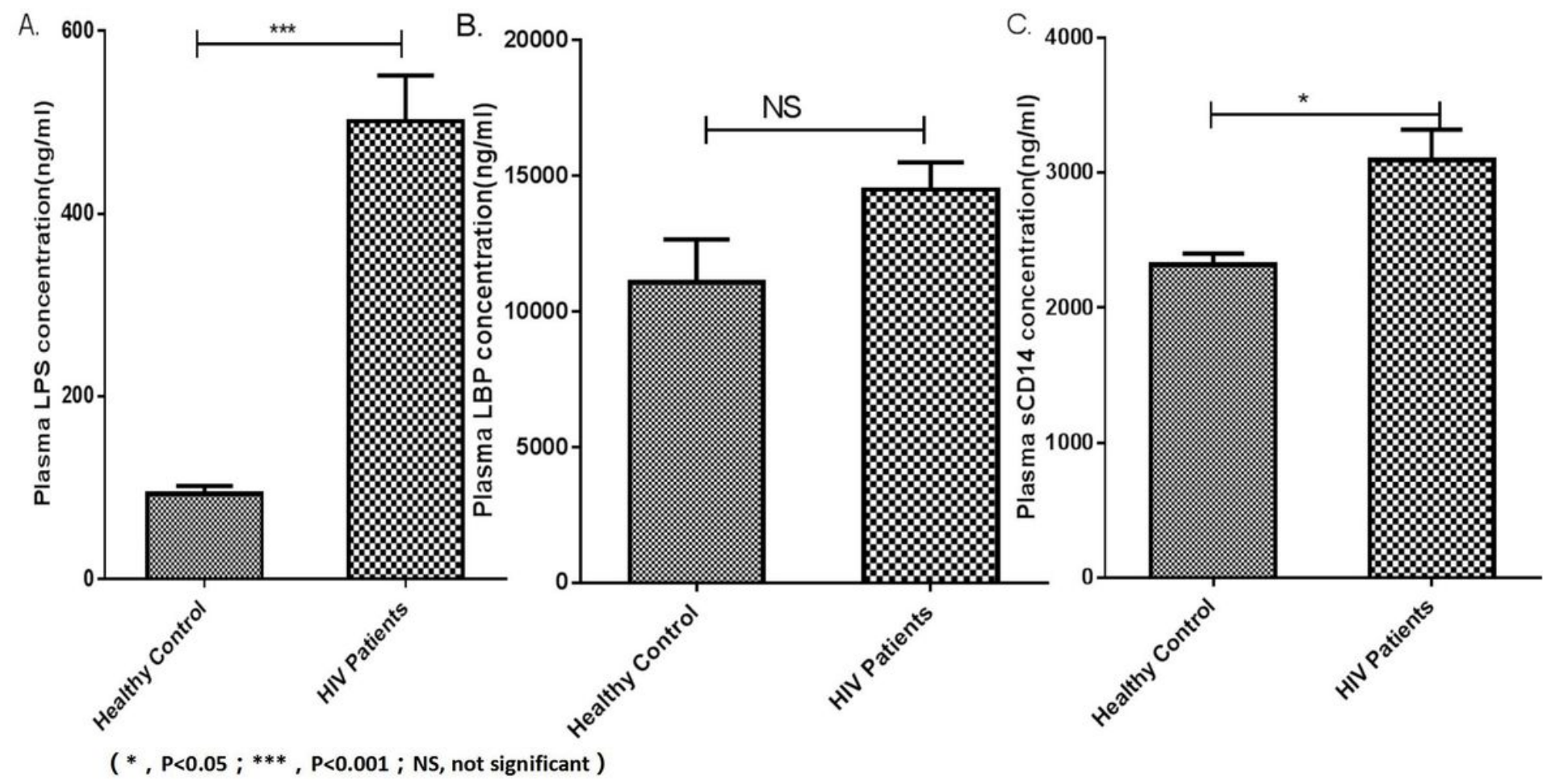

Figure 2

The comparison of baseline plasma LPS, LBP, and SCD14 between HIV patients and healthy volunteers.

\section{Supplementary Files}

This is a list of supplementary files associated with this preprint. Click to download.

- S4DATAnewversion.xlsx

- FigureS3.tif

- FigureS1.tif

- Figures2.tif 